\title{
Biomassa de Egetia densa nos Reservatórios dA HidRoelétrica de Paulo Afonso-bahia
}

\author{
Egeria densa Biomass in the Paulo Afonso-Bahia Hydroelectric Plant \\ NASCIMENTO, P.R.F. ${ }^{2}$, PEREIRA, S.M.B. ${ }^{3}$ e SAMPAIO, E.V.S.B. ${ }^{4}$
}

\begin{abstract}
RESUMO - Com o objetivo de conhecer a produção de biomassa de Egeria densa, foi monitorado o crescimento de 50 ápices de diferentes plantas, em três reservatórios situados na cidade de Paulo Afonso-BA. Os ápices inicialmente medidos receberam uma marcação e foram coletados após 15 dias. O material foi conduzido ao laboratório para medição da biomassa, após secagem a $70{ }^{\circ} \mathrm{C}$. De todos os meses analisados, observou-se nas estações de Taquari e Moxotó maior crescimento em maio/99, com médias de 9,14 \pm 3,6 e 4,2 $\pm 2,1 \mathrm{~cm} /$ ápice/ 15 dias, respectivamente, assim como na estação de Quebra em maio/98 (11,3 \pm 5,3 cm/ ápice/15 dias), correspondendo ao periodo chuvoso. A biomassa também apresentou produções máximas no periodo chuvoso, com 0,26 $\pm 0,17,0,41 \pm 0,06$ e 0,10 \pm 0,5 g MS/ ápice/15 dias nas estações de Taquari, Quebra e Moxotó, respectivamente. E. densa demonstrou ter capacidade de acumular grande quantidade de massa seca, sobretudo no período de maior precipitação, quando geralmente ocorre maior disponibilidade de nutrientes.
\end{abstract}

Palavras-chave: hydrocharitaceae, planta daninha, crescimento, reservatório.

\begin{abstract}
In order to estimate biomass production of Egeria densa, the growth of 50 different plant shoots was monitored at three reservoirs, both located in Paulo Afonso-Bahia. The shoots were marked and had their length measured. Fifteen days later they were measured again, collected, dried at $70^{\circ} \mathrm{C}$ and weighed. The following highest shoot elongation during the 15 days occurred in May 1999 in Taquari and Moxotó and May 1998 in Quebra: 9.14 \pm 3.6, $4.2 \pm 2.1$ and $11.3 \pm$ $5.3 \mathrm{~cm} /$ shoot, respectively, corresponding to the following highest biomass accumulations, 0.26 $\pm 0.17,0.10 \pm 0.05$ and $0.41 \pm 0.06 \mathrm{~g}$ of dry mass per shoot, respectively. Therefore, $\boldsymbol{E}$. densa has a very high capacity of biomass accumulation, mainly during the rainy period when nutrient availability is at the highest.
\end{abstract}

Keywords: hydrocharitaceae, weed, growth, reservoir.

\section{INTRODUÇÃO}

As macrófitas aquáticas possuem papel relevante nos ecossistemas continentais, pois, em condições naturais, mantêm a oxigenação da água, protegem as margens contra a erosão, servem como local de abrigo, alimentação e reprodução para diversos animais, bem como atuam como substrato para a comunidade perifitica. Destacam-se, ainda, como a principal comunidade produtora de biomassa da região litorânea, podendo interferir na estrutura e dinâmica desse ambiente (Esteves, 1998). Apesar dessas relevantes funções, podem causar diversos efeitos negativos, transformando-se em problema quando deixam de coexistir em

1 Recebido para publicação em 13.6.2007 e na forma revisada em 19.1.2008.

Parte da Dissertação da primeira autora.

2 Doutoranda do Programa de Pós-Graduação em Botânica (PPGB) da Universidade Federal Rural de Pernambuco (UFRPE), <prfnascimento@yahoo.com.br>; ${ }^{3}$ UFRPE, Dep. de Biologia, Av. Dom Manuel de Medeiros s/n Dois Irmãos, Recife-PE, 52171030,<soniabp@terra.com.br>; ${ }^{4}$ UFRPE, Dep. de Energia Nuclear, <esampaio@npd.ufpe.br >. 
equilíbrio nos ecossistemas aquáticos, especialmente em reservatórios com fins hidroelétricos.

No Brasil, Egeria densa e E. najas, membros da família Hydrocharitaceae (Cook \& Urmi-König, 1984), têm-se tornado problemáticas, notadamente nos reservatórios de Eng. Souza Dias (SP) e de Itaipu Binacional (Tanaka et al., 2002; Thomaz et al., 2003). Devido à relevância dos impactos causados, alguns trabalhos foram desenvolvidos exclusivamente com essas espécies, como o de Martins et al. (2007), os quais avaliaram o comportamento de diferentes acessos de $E$. densa e $E$. najas em relação ao tratamento com os herbicidas diquat $\mathrm{e}$ fluridone. Os biótipos de $E$. densa foram oriundos dos reservatórios de Jupiá, Nova Avanhandava, Promissão e Salto Grande, e os de E. Najas, de Jupiá, Três Irmãos, Ilha Solteira e Ibitinga. Foi observado que as duas espécies foram controladas de forma eficiente pelo herbicida diquat com apenas uma ou duas aplicações. Rodella et al. (2006) diferenciaram cinco acessos de $E$. densa e três de $E$. najas, coletados no complexo da Companhia Energética de São Paulo (CESP). Foram avaliadas características anatômicas descritivas e quantitativas do limbo foliar, procurando-se obter melhor entendimento sobre as relações dessas estruturas com a penetração e translocação de herbicidas, além de auxiliar na identificação de acessos suscetiveis e resistentes a determinado produto químico. Bini \& Thomaz (2005) observaram a relação entre a ocorrência de $E$. densa e a E. najas presentes no reservatório de Itaipu, localizado no rio Paraná, em resposta a variáveis ambientais (turbidez, profundidade, alcalinidade, $\mathrm{pH}$, condutividade, nitrato e fósforo total). As duas espécies foram encontradas sob circunstâncias ambientais diferentes, sobretudo no que diz respeito a condutividade e coeficiente de atenuação da luz, sendo este último o fator mais preponderante na ocupação dessas espécies. Borges Neto et al. (2004) estudaram os efeitos do fotoperíodo e da temperatura na intensidade de doença causada pelo fungo Fusarium graminearum, considerado um agente biocontrolador, nas macrófitas Egeria densa e E. najas.

No Nordeste, desde 1984, os reservatórios do Complexo Hidroelétrico de Paulo Afonso-BA vêm sofrendo diversos transtornos operacionais, devido à colonização por E. densa, considerada no Brasil uma das plantas daninhas submersas de maior expressão nesses ecossistemas. Como reflexo dessa colonização, foi necessário realizar alguns trabalhos nesse ambiente, como o desenvolvido por Oliveira et al. (2005), que determinaram a capacidade de regeneração de $E$. densa, em diferentes profundidades (0-2, 2-6 e 6-9 m), depois que as plantas foram arrancadas em estações de coletas, previamente determinadas, localizadas no Complexo Hidroelétrico de Paulo Afonso-BA. As produções nas três profundidades, especialmente nas áreas mais rasas, indicaram que $E$. densa possui elevada capacidade de acumulação de biomassa. Sampaio \& Oliveira (2005) testaram a possibilidade de aproveitamento de $E$. densa como adubo orgânico, comparando sua eficiência com esterco, em plantio de milho. As adubações com esta macrófita incorporaram grande quantidade de nutrientes no solo e resultaram em produção de grãos de milho $\left(3,5\right.$ a $\left.8,5 \mathrm{tha}^{-1}\right)$ e palha $(4,3$ a $8,8 \mathrm{tha}^{-1}$ ) muito maior que a da testemunha $\left(0,3\right.$ e $\left.1,2 \mathrm{t} \mathrm{ha}^{-1}\right)$. Batista et al. (2004) e Oliveira et al. (2004), após avaliarem o efeito da adição do feno de E. densa em substituição ao feno de tifton sobre a digestibilidade dos nutrientes em caprinos jovens, concluíram que esta macrófita tem potencial forrageiro, desde que fornecida em baixa proporção na ração ou por um curto periodo de tempo. Esses autores apresentam essa restrição devido ao fato de que esta espécie pode absorver metais pesados, os quais, em altas concentrações, podem representar riscos à saúde dos animais.

Assim, o presente trabalho teve como objetivo obter dados quantitativos do crescimento e da produção de biomassa da $E$. densa, a fim de contribuir com informações sobre a sua ecologia.

\section{MATERIAL E MÉTODOS}

A área de estudo situou-se no Complexo Hidroelétrico de Paulo Afonso, no município de Paulo Afonso (09 21' 42"S e 38 $16^{\prime}$ ' 19" W), no Estado da Bahia. Em razão da representatividade dos prados da $E$. densa, foram estabelecidas três estações de coleta: duas localizadas no Reservatório de Delmiro Gouveia, Taquari $\left(09^{\circ} 23^{\prime} 24^{\prime \prime S}\right.$ e $\left.38^{\circ} 12^{\prime \prime} 15,6^{\prime \prime} \mathrm{W}\right)$ e Quebra (09 
22’ 40,7"S e $38^{\circ} 12^{\prime \prime} 13^{\prime \prime} \mathrm{W}$ ), e uma no Reservatório Apolônio Sales, Moxotó (09 22' 24,7"S e $\left.38^{\circ} 13^{\prime \prime} 27,6^{\prime \prime} \mathrm{W}\right)$. As coletas foram realizadas nos meses de fevereiro, maio, setembro e novembro de 1998 e fevereiro, maio, agosto e novembro de 1999. Em cada estação foram escolhidos, de forma aleatória, 50 ápices de diferentes individuos de E. densa. Cada ápice recebeu um marcador plástico (abraçadeira), estabelecendo-se o comprimento inicial da planta amostrada, sendo identificado a partir de uma numeração contida em uma placa metálica. Após 15 dias, os ápices foram cortados no nível da abraçadeira, acondicionados em sacos plásticos e transportados para o laboratório de Ficologia (LABOFIC/UFRPE). No laboratório, os ápices cortados foram mesurados para obtenção do comprimento final e levados à estufa $\left(70^{\circ} \mathrm{C}\right)$, até atingirem massa seca constante. As análises dos dados foram realizadas utilizando-se o programa Statistica (Statsoft, 1995), a partir do qual foi realizado o teste de normalidade e, com base neste, optou-se pelo teste não-paramétrico Kruskal-Wallis, a 5\% de probabilidade; a comparação das médias foi feita por meio do teste de Tukey a $5 \%$ de probabilidade.

\section{RESULTADOS E DISCUSSÃO}

Os valores do crescimento dos ápices de $E$. densa variaram nas três estações de coleta (Figuras 1, 2 e 3). Pode-se constatar que não

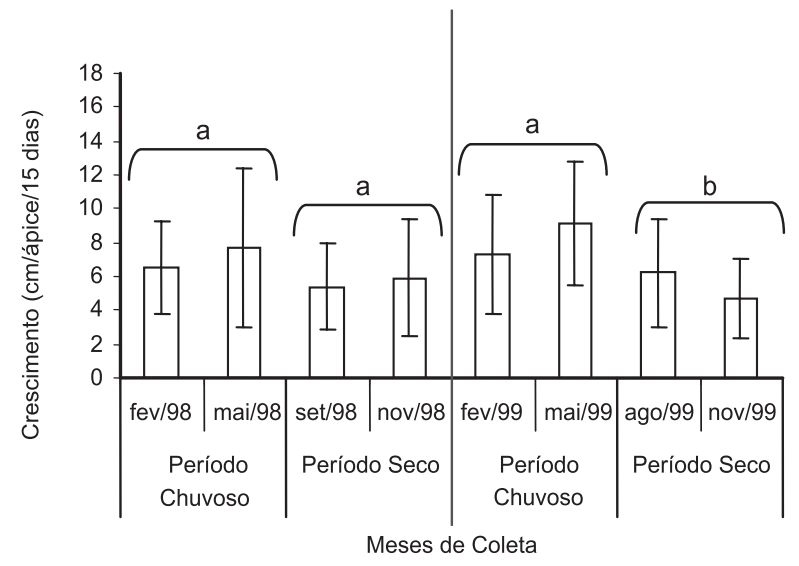

As letras diferentes indicam diferenças significativas entre os períodos anuais (chuvoso e seco).

Figura 1 - Crescimento dos ápices de E. densa durante o período de fev. a nov. 98 e fev a nov. 99, na Estação de Taquari, Reservatório Delmiro Gouveia-BA. houve diferença estatística entre os meses de coleta, provavelmente devido aos elevados desvios-padrão, o que demonstra grande variabilidade dos dados. Das três estações de coletas analisadas, as plantas que ocorreram em Moxotó apresentaram menor média no mês de nov./98. Esse fato pode ser explicado porque nesse período os ápices de $E$. densa apresentavam-se recobertos por grande quantidade de microalgas da comunidade perifitica, as quais podem ter interferido na captação da luz pela macrófita, causando menor produtividade. Comportamento semelhante foi observado por Feijoó et al. (1996), quando verificaram competição de $E$. densa com microalgas não só na disputa pela luz, mas também pela disponibilidade de nutrientes (principalmente do nitrato, o qual variou de 8 a $57 \mathrm{mg} \mathrm{L}^{-1}$ ) e pela competição interespecífica, sobretudo com macrófitas flutuantes (por exemplo, Lemma gibba), pois elas reduzem sensivelmente os niveis de luminosidade. No presente trabalho, quando analisados os meses de coleta isoladamente, os valores de crescimento dos ápices não mostraram diferenças significativas. Contudo, verificou-se distinção quando levado em consideração o período anual (chuvoso e seco). Essa diferença foi considerada significativa, sendo o período chuvoso (17\%) maior em relação ao período seco, independentemente da estação de coleta.

Esse fato pode indicar que as plantas de $E$. densa investiram suas reservas no alongamento dos ápices, representando uma

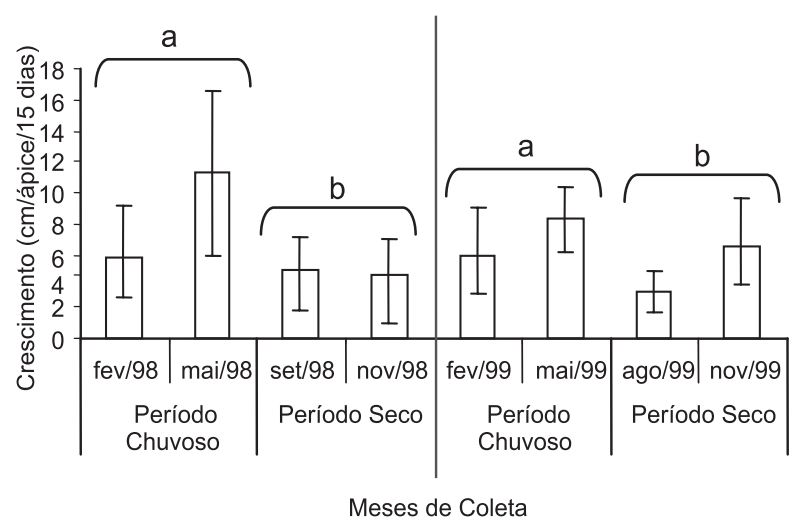

As letras diferentes indicam diferenças significativas entre os períodos anuais (chuvoso e seco).

Figura 2 - Crescimento dos ápices de E. densa durante o período de fev. a nov. 98 e fev a nov. 99, na Estação de Quebra, Reservatório Delmiro Gouveia-BA.

Planta Daninha, Viçosa-MG, v. 26, n. 3, p. 481-486, 2008 
adaptação morfológica à baixa luminosidade. A esse respeito, Barko \& Smart (1981) comentam que $E$. densa, assim como $E$. najas, além de se desenvolverem bem em locais com alta transparência da água, também possuem habilidade para alongar-se e formar dossel, em ambientes com transparência limitada. Fato similar foi observado por Tavechio \& Thomaz (2003) ao analisarem a taxa de fotossintese e crescimento de E. najas, evidenciando que esta espécie pode apresentar baixo requerimento por radiação.

Com relação à produção de biomassa dos

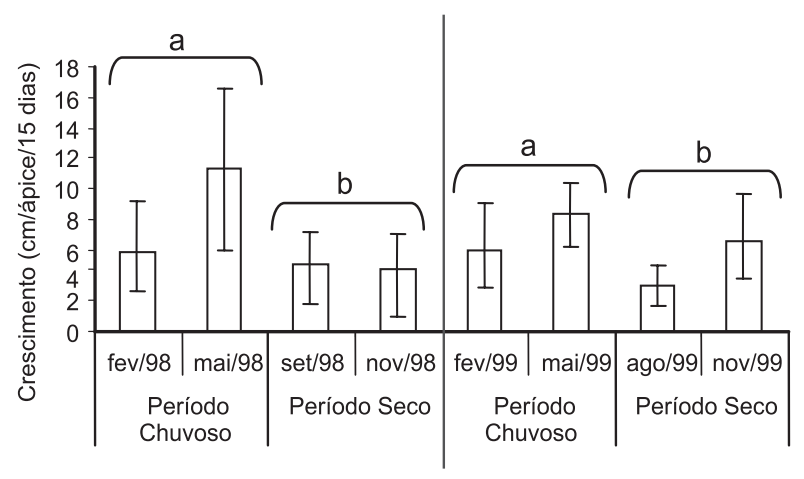

Meses de Coleta

As letras diferentes indicam diferenças significativas entre os períodos anuais (chuvoso e seco).

Figura 3 - Crescimento dos ápices de E. densa durante o período de fev a nov. 98 e fev. a nov. 99, na estação de Moxotó, Reservatório Apolônio Sales-BA.

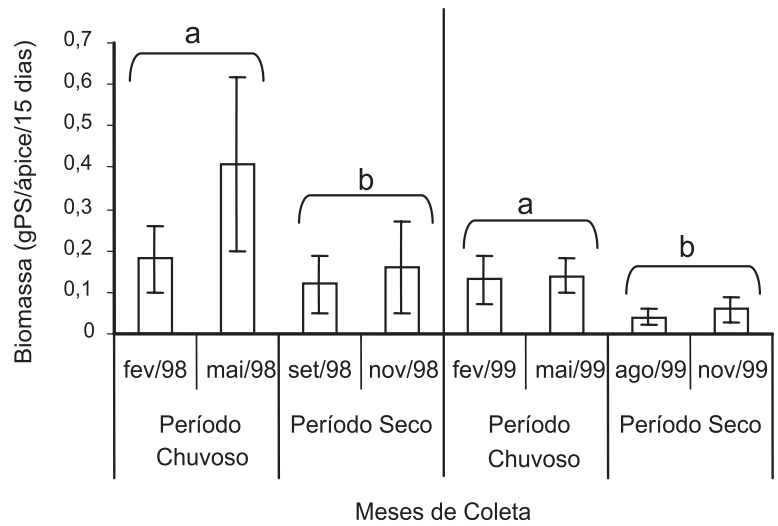

As letras diferentes indicam diferenças significativas entre os períodos anuais (chuvoso e seco)

Figura 5 - Biomassa dos ápices de $E$. densa durante o período de fev. a nov. 98 e fev. a nov. 99, na estação de Quebra, Reservatório Delmiro Gouveia-BA.

Planta Daninha, Viçosa-MG, v. 26, n. 3, p. 481-486, 2008 ápices apresentada pelas plantas de $E$. densa, verificou-se também grande variação dos dados (Figuras 4, 5 e 6). Contudo, a análise estatística evidenciou que não houve diferença entre os meses de coleta, assim como foi verificado para o crescimento dos ápices. Entretanto, comparando-se os valores nos dois períodos anuais, foi observada diferença estatística para as estações de coleta de Taquari e Quebra (Figuras 4 e 5), onde a biomassa no período chuvoso foi $15 \%$ maior que no período seco. Esse fato pode estar relacionado com elevados teores de nutrientes registrados, geralmente, no período

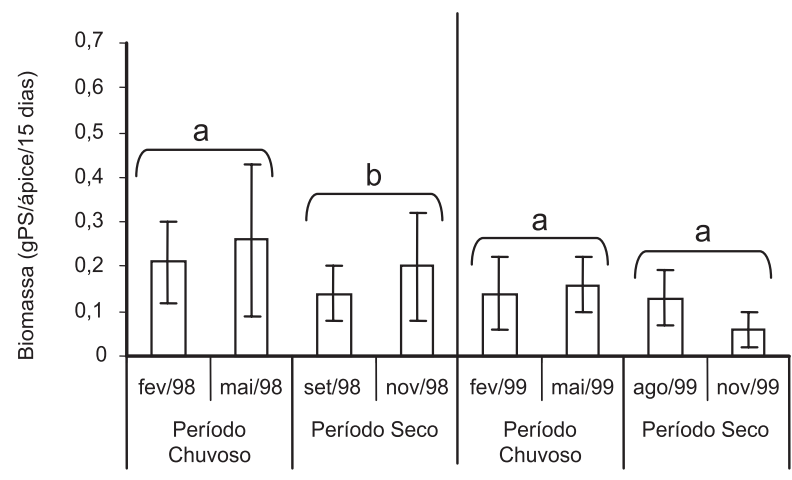

Meses de Coleta

As letras diferentes indicam diferenças significativas entre os períodos anuais (chuvoso e seco).

Figura 4 - Biomassa dos ápices de E. densa durante o período de fev a nov. 98 e fev. a nov. 99, na estação de Taquari, Reservatório Delmiro Gouveia-BA.

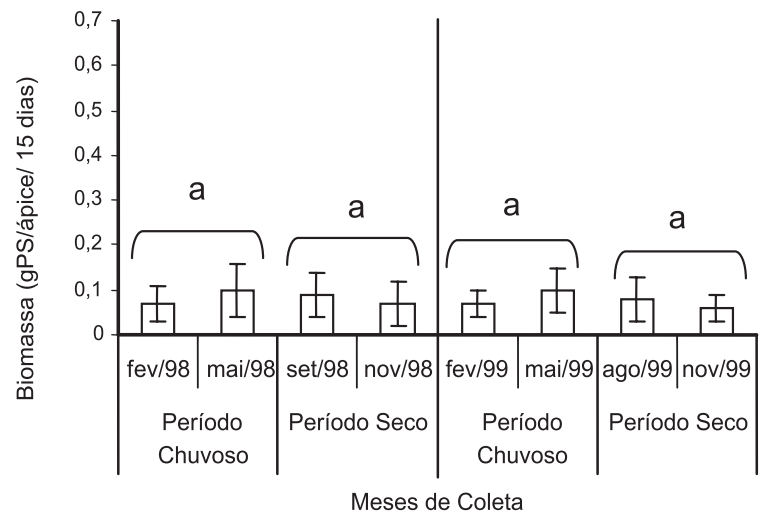

As letras diferentes indicam diferenças significativas entre os períodos anuais (chuvoso e seco).

Figura 6 - Biomassa dos ápices de $E$. densa durante o período de fev. a nov. 98 e fev. a nov. 99, na estação de Moxotó, Reservatório Delmiro Gouveia-BA. 
chuvoso. Alguns autores já relataram que no período chuvoso há maior disponibilidade de nutrientes, como Junk (1970), o qual observou grande quantidade de material alóctone trazido pelas cheias, o que provocou acúmulo de nutrientes em lagos da região amazônica, proporcionando intenso crescimento de macrófitas. De acordo com Henry et al. (1999), o regime de precipitação tem grande importância na remoção e transporte de sedimentos e nutrientes dos ecossistemas terrestres para os ambientes aquáticos, sendo considerado uma das principais fontes da eutrofização. Conforme Severi, W. (comunicação pessoal), maiores precipitações geralmente elevam os niveis de nutrientes dos reservatórios do Complexo Hidroelétrico de Paulo Afonso, sobretudo as concentrações de nitrogênio amoniacal. De acordo com essa comunicação, esse aumento se deve ao intenso aporte de resíduos de natureza diversa (plástico, resíduos orgânicos etc.), principalmente nos locais com interferência de áreas agrícolas e/ou centros urbanos, como é o caso da cidade de Paulo Afonso. Braga et al. (1999) observaram aumento nos valores de nutrientes nos reservatórios estudados, notadamente do nitrato- $\mathrm{N}$, durante o período das chuvas, indicando ser uma conseqüência do processo de enxurrada nas áreas de maior ação antrópica e de atividades agropecuárias na região.

É importante destacar a ocorrência de plantas desprendidas do sedimento sobre as plantas fixas especificamente na estação de Quebra, no mês de ago./99. Esse desprendimento deve ter sido causado pela correnteza das águas, uma vez que nas áreas próximas a esta estação houve intensa turbulência da água (Severi, W. - comunicação pessoal). O sombreamento causado pelas plantas soltas pode ter provocado a diminuição do tamanho das plantas fixas ou até mesmo a morte por falta de iluminação adequada, contribuindo para o decréscimo da biomassa nesse mês (Figura 5). Aliado a esse fato, também houve necessidade de se rebaixar o nível da água, com a finalidade de realizar reparo nas paredes da barragem. Sabe-se que, quando ocorre abaixamento seguido de rápida elevação, pode haver interferência na produtividade de macrófitas devido a alterações provocadas sobretudo na disponibilidade da luz (Blom et al., 1990).
De maneira geral, durante o período de estudo, houve diferença estatística nas taxas de crescimento e biomassa de $E$. densa entre as três estações de coleta, demonstrando que no mesmo reservatório podem existir diferentes produtividades de biomassa em sítios de reprodução distintos - fato também verificado por Martins et al. (2005).

A determinação de sítios de reprodução e de suas respectivas importâncias na disseminação para outros locais torna-se fundamental para o desenvolvimento de estratégias de manejo de espécies de plantas aquáticas imersas presentes nos reservatórios com fins de geração de energia (Martins et al., 2005). Dessa forma, as estimativas de biomassa obtidas no presente trabalho apontaram E. densa como uma planta de grande potencial para armazenar massa seca, disponibilizando grandes estoques de nutrientes, em curtos intervalos de tempo. No que diz respeito a pesquisas que avaliam variações nas concentrações de nutrientes em plantas aquáticas, tem-se o exemplo de Corrêa et al. (2003), os quais determinaram a composição química e bromatológica de três espécies, entre elas $E$. densa, proveniente de controle mecânico realizado no reservatório de Jupiá (SP), levando em consideração possiveis diferenças entre os periodos de verão e inverno. Em análises das concentrações de K, $\mathrm{Ca}, \mathrm{Mg}, \mathrm{Al}, \mathrm{Co}, \mathrm{Cu}, \mathrm{Fe}, \mathrm{Si}, \mathrm{Zn}, \mathrm{P}, \mathrm{S}, \mathrm{N}$ e C, esses autores verificaram maior concentração dos elementos nas plantas coletadas durante o verão.

$O$ fato de $E$. densa acumular grande quantidade de massa seca a faz ser indicada para produção de ração animal (Oliveira et al., 2004) ou adubo orgânico (Sampaio \& Oliveira, 2005; Sampaio et al., 2007) como alternativa de ordem econômica e ambiental.

\section{AGRADECIMENTOS}

Os autores agradecem o apoio financeiro recebido da Companhia Hidroelétrica do São Francisco (CHESF), através do convênio entre a CHESF / Fundação Apolônio Salles de Desenvolvimento Educacional (FADURPE), e ao Conselho Nacional de Desenvolvimento Científico e Tecnológico - CNPq, pela concessão das bolsas de Mestrado e de Produtividade de Pesquisa. 


\section{LITERATURA CITADA}

BARKO, J. W.; SMARTH, M. S. Comparative influences of ligth and temperature on the growth and metabolism of selected submerged freshwater macrophytes. Ecol. Monogr., v. 51, n. 2 , p. $219-235,1981$.

BATISTA, A. M. V. et al. Avaliação do feno de Egeria densa na alimentação de carneiros. R. Bras. Zootec., v. 33, n. 5, p. $1309-1315,2004$

BINI, L. M.; THOMAZ, S. M. Prediction of Egeria najas and Egeria densa occurrence in a large subtropical reservoir (Itaipu Reservoir, Brasil - Paraguay). Aquat. Bot., v. 83, n. 3, p. 227-238, 2005.

BLOM, J. H. et al. Adaptations to flooding in plants from rivers areas. Aquat. Bot., v. 38, n. 1, p. 29-47, 1990

BORGES NETO, C. R.; GORGATI, C. Q.; PITELLI, R. A. Influência do fotoperíodo e da temperatura na intensidade de doença causada por Fusarium graminearum em Egeria densa e E. Najas. Fitopatol. Bras., v. 29, n. 3, p. 252-258, 2004.

BRAGA, J. D. et al. Programa de controle de macrófitas aquáticas no Complexo Hidroelétrico de Paulo Afonso e na UHE Itaparica. In: SNPTEE - SEMINÁRIO NACIONAL DE PRODUÇÃO E TRANSMISSÃO DE ENERGIA ELÉTRICA, 15., Foz do Iguaçu, 1999. Seminário... Foz do Iguaçu: GIA/15, 1999. p. 1-4

COOK, C. D. K.; URMI-KÖNIG, K. A revision of the genus Egeria (Hidrocharitaceae). Aquat. Bot., v. 19, n. 1, p. $73-96,1984$

CORRÊA, M. R.; VELINI, E. D.; ARRUDA, D. P. Composição química de Egeria densa, Egeria najas e Ceratophyllum demersum. Planta Daninha, v. 21, n. 1, p. 7-13, 2003.

ESTEVES, F. A. Fundamentos da limnologia. Rio de Janeiro: Interciência/FINEP, 1998. 602 p.

FEIJOÓ, C. S. et al. Factors influencing biomass and nutrient content of the submersed macrophyte Egeria densa Planch. in pampasic stream. Hydrobiologia, v. 341, n. 1, p. 21-26, 1996.

HENRY, R.; SANTOS, A. A. N.; CAMARGO, Y. R Transportes de sólidos suspensos, N e P total pelos rios Paranapanema e Taquari e uma avaliação de sua exportação na Represa Jurumirim. In: HENRY, R. (Ed.). Ecologia de reservatórios: estrutura, função e aspectos sociais. Botucatu: FUNDIBIO - FAPESP, 1999. p. 597-626.
JUNK, W. J. Investigation on the ecology and production biology of the "floating - meadows" (PaspaloEichinochloetum) on the middle Amazon I. The floating vegetation and ecology. Amazoniana, v. 2, p. 449-495, 1970.

MARTINS, D.; MARCHI, S. R.; COSTA, N. V. Estudo da movimentação de plantas aquáticas imersas presentes no reservatório da UHE Eng. Souza Dias - Jupiá. Planta Daninha, v. 23, n. 2, p. 351-358, 2005.

MARTINS, D. et al. Sensibilidade de diferentes acessos de Egeria najas e Egeria densa aos herbicidas diquat e fluridone. Planta Daninha, v. 25, n. 2, p. 351-358, 2007

OLIVEIRA, N. M. B. et al. Capacidade de regeneração de Egeria densa nos reservatórios de Paulo Afonso, BA. Planta Daninha, v. 23, n. 2, p. 7-13, 2005.

OLIVEIRA, R. J. F. et al. Efeito da adição de Egeria densa sobre a digestibilidade e balanço de ntrogênio em caprinos.

Arch. Zootec., v. 53, n. 1, p. 175-184, 2004.

RODELLA, R. A. et al. Diferenciação entre Egeria densa e Egeria najas pelos caracteres anatômicos foliares. Planta Daninha, v. 24, n. 2, p. 211-220, 2006

SAMPAIO, E. V. S. B.; OLIVEIRA, N. M. B

Aproveitamento da macrófita aquática Egeria densa como adubo orgânico. Planta Daninha, v. 23, n. 2, p. 169-174, 2005.

SAMPAIO, E. V. S. B.; OLIVEIRA, N. M. B.; NASCIMENTO, P. R. F. Eficiência da adubação orgânica com esterco bovino e com Egeria densa. R. Bras. Ci. Solo, v. 31, n. 4 , p. $995-1002,2007$

STATSOFT. Statistica for Windows. Version 5.0. Cary: 1995.

TANAKA, R. H. et al. Ocorrência de plantas nos reservatórios da Companhia Energética de São Paulo. Planta Daninha, v. 20, p. 99-111, 2002. (Edição Especial).

TAVECHIO, W. L. G.; THOMAZ, S. M. The effects of light on the growth and photosynthesis os Egeria densa Planchon. Braz. Arch. Biol. Technol., v. 46, n. 2, p. 203209, 2003.

THOMAZ, S. M.; BINI, L. M.; PAGIORO, T. A Macrófitas aquáticas em Itaipu: ecologia e perspectivas para o manejo. In: THOMAZ, S. M.; BINI, L. M. (Eds.) Ecologia e manejo de macrófitas aquáticas. Maringá: EDUEM, 2003. p. 319-341. 